\title{
STRUCTURAL TRANSFORMATIONS VERSUS HARD PARTICLES MOTION IN THE BRASS INGOTS
}

\begin{abstract}
A mathematical method for the forecast of the type of structure in the steel static ingot has been recently developed. Currently, the method has been applied to structural zones prediction in the brass ingots obtained by the continuous casting. Both the temperature field and thermal gradient field have been calculated in order to predict mathematically the existence of some structural zones in the solidifying brass ingot. Particularly, the velocity of the liquidus isotherm movement and thermal gradient behavior versus solidification time have been considered. The analysis of the mentioned velocity allows the conclusion that the brass ingots can evince: chilled columnar grains-, (CC), fine columnar grains-, (FC), columnar grains-, (C), equiaxed grains zone, (E), and even the single crystal, (SC), situated axially. The role of the mentioned morphologies is analyzed to decide whether the hard particles existing in the brass ingots can be swallowed or rejected by the solid / liquid (s/l) interface of a given type of the growing grains. It is suggested that the columnar grains push the hard particles to the end of a brass ingot during its continuous casting.

Keywords: Continuously cast ingot; Mathematical forecast of structural zones; Hard particles in the brass
\end{abstract}

\section{Mathematical prediction of structural transformations}

Localization of some structural zones in the steel static ingot can be predicted mathematically, [1]. The method takes the extreme points (minima and maxima) and also points of inflection of some considered functions into account. However, the method is able to predict the fundamental structural transformation observed in the massive ingot, only. It is not possible to predict sedimentary cones appearance as well as the " $\mathrm{A}$ " and "V" segregates formation by this method, Fig. 1. To some extent, the method is based on the Prof. J.D. Hunt's fundamental paper associated with the analysis of undercooling, [2]. The current, innovative mathematical method for the structural zones predictions and resultant structural transformation is applied to the forecast of the structural transitions in the continuously cast brass ingots.

The essential role playing by the so-called contact layer (air gap) is considered in the current simulation analogously to some models considering both the mushy zone and contact layer influences on the ingot structure formation, [3-5].

Generally, some predictions of the structural transitions in the static massive ingots and continuously cast ingots are the result of the analysis dealing with the difference between constrained and unconstrained solidification, [6-34].
Outline of the steel static ingot morphology and its formation in solidification time predicts the following structural zones: a/ chilled equiaxed grains, CE, Fig. $1 \mathrm{~m}$, b/ columnar cells (treated as some single crystals), C, Fig. 11, c/ columnar dendrites, CD, Fig. $1 \mathrm{j}$,

d/ lower sedimentary cone, LSC, Fig 1o,

e/ upper sedimentary cone, USC, Fig. 1n,

f/ lower "A" segregates, LAS, Fig. 1k,

g/ upper "A" segregates, HAS, Fig. 1f,

h/ "V" segregates, VS, Fig. 1e,

i/ equiaxed grains, E, coexisting with columnar dendrites, Fig. 1d,

j/ equiaxed grains, E, coexisting with the segregates, Fig. 1g, $\mathrm{k} /$ equiaxed grains, E, coexisting with the shrinkage cavity and axial porosity, Fig. 1c.

The switching point in the static ingot, Fig. 1i, is a virtual place / time at which the thermophoresis is the winner in the competition between thermophoresis itself and viscosity gradient, [1].

The viscosity gradient is responsible for the formation of the sedimentary cones in the static ingot, whereas the thermophoresis is connected with formation of the shell / crust shape of the solid, Fig. 1.

The above analysis postulates that the equiaxed structure is dominant in the steel ingot subjected to the static solidification. It results from the fact that the static solidification is an

INSTITUTE OF METALLURGY AND MATERIALS SCIENCE, 25 REYMONTA STR., 30059 KRAKÓW, POLAND

** INSTITUTE OF APPLIED MATHEMATICS AND MECHANICS, 74 ROSA LUXEMBURG STR., 83-114 DONETSK, UKRAINE

*** KGHM - POLISH COPPER COMPANY, 48 SKŁODOWSKIEJ-CURIE STR., 59-301 LUBIN, POLAND

**** AGH UNIVERSITY OF SCIENCE AND TECHNOLOGY, 23 REYMONTA STR., 30-059 KRAKÓW, POLAND

Corresponding author: w.wolczynski@imim.pl@polsl.pl 


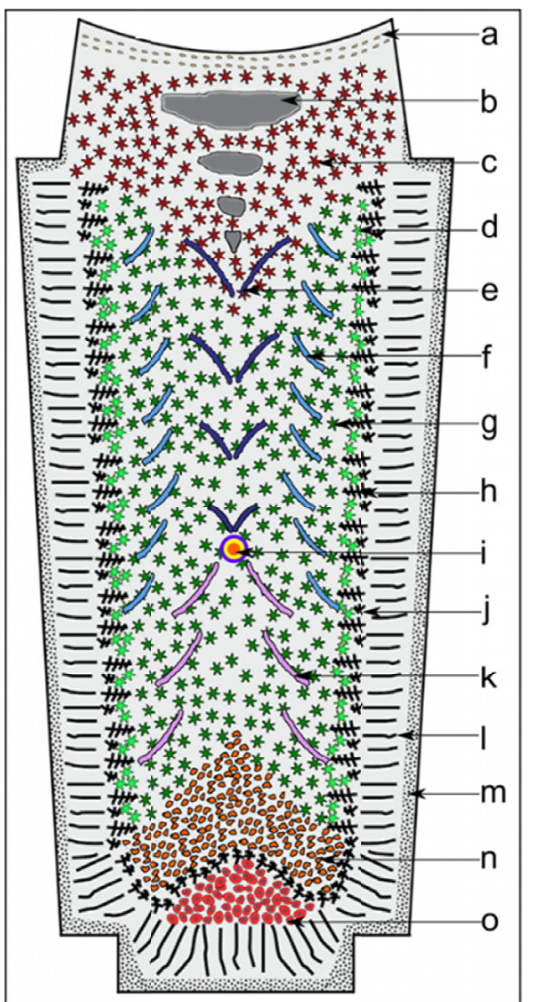

Fig. 1. Outline: steel static ingot structure and its sequential formation

unsteady process and the solidification rate decreases in time due to slow cooling.

Some observations of the structure revealed in the continuously cast ingots confirms that the columnar structure can be dominant in these castings, Fig. 2a. It results from the fact that the continuous casting is the stationary process (apart from the initial transient period of this process) and the cooling is usually intensive.

The presence of the equiaxed structure as a dominant morphology in the continuously cast brass ingots is also possible, Fig. 2b. The equiaxed grains form when the local thermal gradient is negative whereas the thermal gradient is locally positive for the columnar grains formation, $[8,35]$.

It should be emphasized that the initial transient period of the ingots continuous casting follows the static ingot solidification to some extent as described in details, [6].

The continuously cast brass ingot can also evinces the presence of the single crystal situated axially, Fig. 2a. It results from the fact that the thermal gradient direction (heat transfer) was changed drastically from the radial to the axial one.

When the axial heat transfer occurs and ingot translation in the crystallizer is sufficiently small (and accompanied with a properly high thermal gradient at the $\mathrm{s} / \mathrm{l}$ interface) then the single crystal formation can be expected, Fig. 2a.

Not every structural zone observed in the steel static ingots, $[1,7,9,11,14,20,22-25,27,29,30,32]$, can be revealed in the continuously cast brass ingots. Moreover, some of them cannot be formed since the brass ingots do not contain relevant additions (apart from the hard particles). Moreover, the brass ingots are not the massive castings.

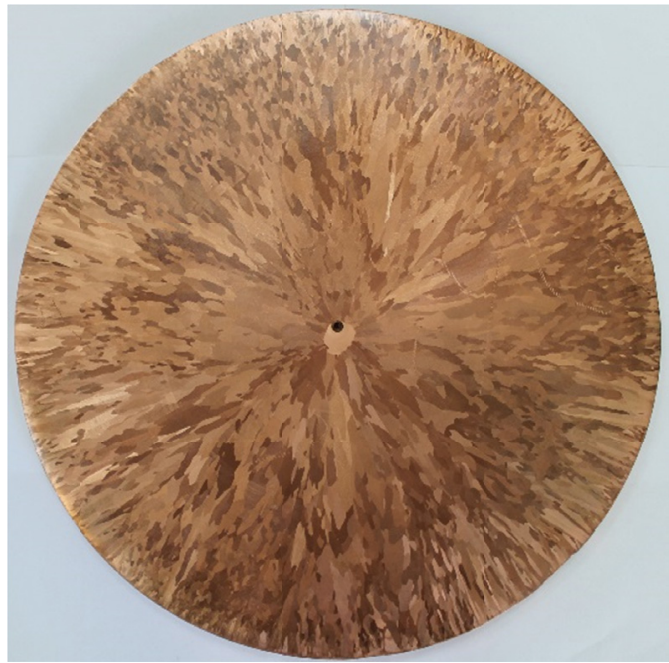

Fig. 2a. Morphology of the continuously cast brass ingot revealing columnar (dominant), equiaxed grains and the single crystal situated axially.

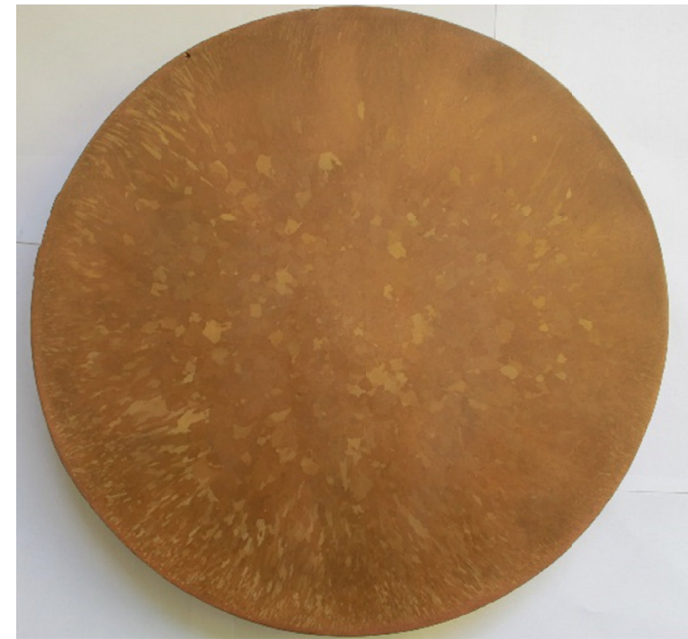

Fig. 2b. Morphology of the continuously cast brass ingot revealing columnar grains with the equiaxed (dominant) structure.

\section{Model for structural zones predictions in the continuously cast brass ingots}

The recently developed numerical model for the continuous casting $[4,12,13]$, is modified and applied to the current method for the structural zones forecast. The heat balance in the method is as follows:

$$
\begin{gathered}
c_{e f}(T) \cdot \rho(T) \cdot \frac{\partial T}{\partial t}=\frac{\partial}{\partial r}\left[\lambda(T) \cdot \frac{\partial T}{\partial r}\right]+\frac{\lambda(T)}{r} \cdot \frac{\partial T}{\partial r} \\
T=T(t, r), \quad r \in\left[0, R_{m}\right] \\
c_{e f}(T)= \begin{cases}c_{b}(T), & T<T_{S} \\
c_{b}(T)+\frac{L}{T_{L}-T_{S}}, & T_{S} \leq T \leq T_{L} \\
c_{b}(T), & T>T_{L}\end{cases}
\end{gathered}
$$


Eq. (1) requires to consider some boundary conditions at: a/ surface of the solid shell being in contact with the air gap, Fig. 3,

$$
\begin{aligned}
\left.\lambda(T) \frac{\partial T}{\partial r}\right|_{r=R}= & \frac{\lambda_{g}}{\delta_{g}}\left(\left.T\right|_{r=R+\delta_{g}}-\left.T\right|_{r=R}\right)+ \\
& +\sigma\left[\left(\left.T\right|_{r=R+\delta_{g}}\right)^{4}-\left(\left.T\right|_{r=R}\right)^{4}\right]
\end{aligned}
$$

b/ surface of the graphite layer being in contact with the air gap, Fig. 3

$$
\begin{aligned}
\left.\lambda_{g r}(T) \frac{\partial T}{\partial r}\right|_{r=R+\delta_{g}} & =\frac{\lambda_{g}}{\delta_{g}}\left(\left.T\right|_{r=R+\delta_{g}}-\left.T\right|_{r=R}\right)+ \\
& +\sigma\left[\left(\left.T\right|_{r=R+\delta_{g}}\right)^{4}-\left(\left.T\right|_{r=R}\right)^{4}\right]
\end{aligned}
$$

c/ surface of the graphite layer being in contact with the crystallizer, Fig. 3,

$$
\left.\lambda_{g r}(T) \frac{\partial T}{\partial r}\right|_{r=R_{m^{\prime}}-}=\alpha_{g m}\left(\left.T\right|_{r=R_{m}{ }^{\prime}+}-\left.T\right|_{r=R_{m^{\prime}}-}\right)
$$

d/ surface of the crystallizer being in contact with the graphite layer, Fig. 3,

$$
\left.\lambda_{m}(T) \frac{\partial T}{\partial r}\right|_{r=R_{m^{\prime}}+}=\alpha_{g m}\left(\left.T\right|_{r=R_{m^{\prime}}{ }^{+}}-\left.T\right|_{r=R_{m^{\prime}}{ }^{\prime}}\right)
$$

e/ surface of the crystallizer being in contact with the cooling water, Fig. 3,

$$
\left.\lambda_{m}(T) \frac{\partial T}{\partial r}\right|_{r=R_{m}}=\alpha_{0}\left(\left.T\right|_{r=R_{m}}-T_{w}\right)
$$

f/ moving surface of the solid shell being in contact with air,

$$
\left.\lambda(T) \frac{\partial T}{\partial r}\right|_{r=R}=\alpha_{a}\left(T_{a}-\left.T\right|_{r=R}\right)+\sigma_{a}\left[T_{a}^{4}-\left(\left.T\right|_{r=R}\right)^{4}\right]
$$

where $\rho$ is density; $c_{b}$ - brass specific heat; $\lambda_{g}, \lambda_{g r}, \lambda_{m}$ - thermal conductivity coefficient in air, graphite, crystallizer, respectively; $\delta_{g}$ - thickness of air gap; $\sigma-$ Stefan-Boltzmann constant of radiation; $\alpha_{g m}$ - coefficient of heat transfer between the graphite and crystallizer; $\alpha_{a}$ - coefficient of heat transfer between the ingot and the surrounding air; $\sigma_{a}-$ Stefan-Boltzmann constant of radiation (outside of crystallizer).

Eq. (1) allows to predict the structural transformations expected in the continuously cast brass ingot for a given rate of the ingot translation in the crystallizer and also for a given height of the crystallizer.

The mentioned structural transitions are defined by some points of inflection and extreme points which appear on the calculated functions. First of all, it is expected that the FCCT (Fine Columnar into Columnar) and CET (Columnar into Equiaxed) transitions can be well defined by the current method for the structural zones forecast.

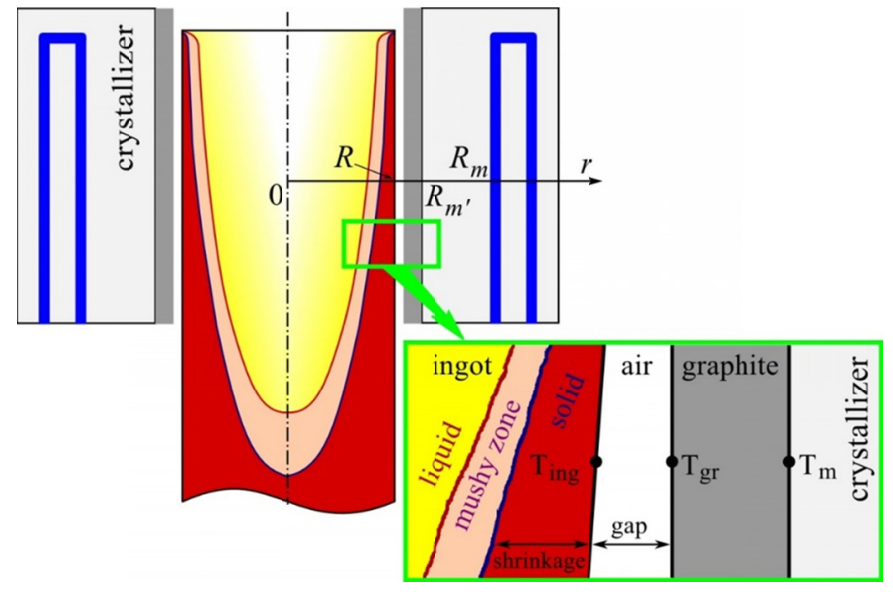

Fig. 3. Model of the system for the continuous casting of brass ingot shown in the $x, r$-coordinates; $T_{i n g}, T_{g r}$ - solid shell surface, graphite surface temperatures, respectively; expanding air gap due to shrinkage phenomenon and mushy zone are applied to the outline

The results of the simulation leading to the forecast of the mentioned structural transformations are shown in Fig. 4 for the $\mathrm{Cu}-20 \mathrm{Zn}$ alloy.

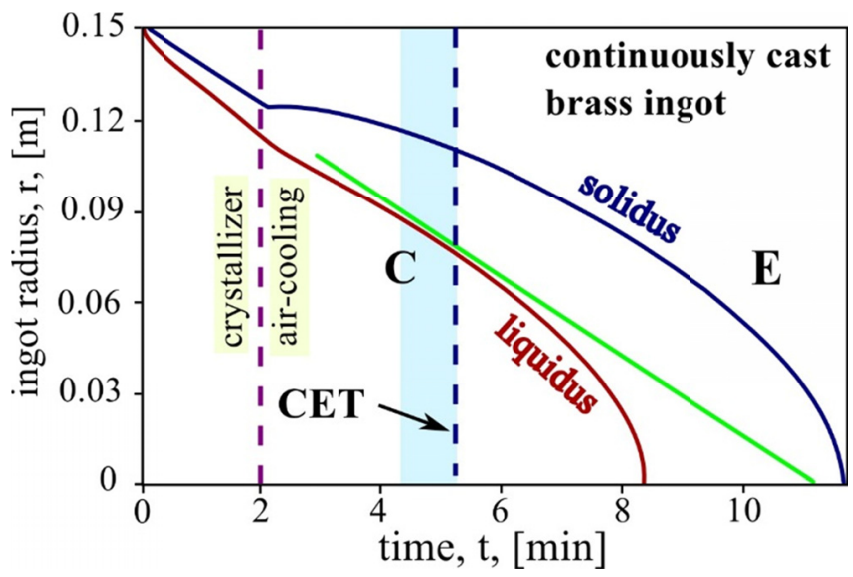

Fig. 4a. Forecast of the CET - transformation for a given rate of brass ingot movement in the crystallizer (equal to $0.4[\mathrm{~m} / \mathrm{min}]$ ), as suggested by the local maximum in the STSM (Space-Time-Structure Map)

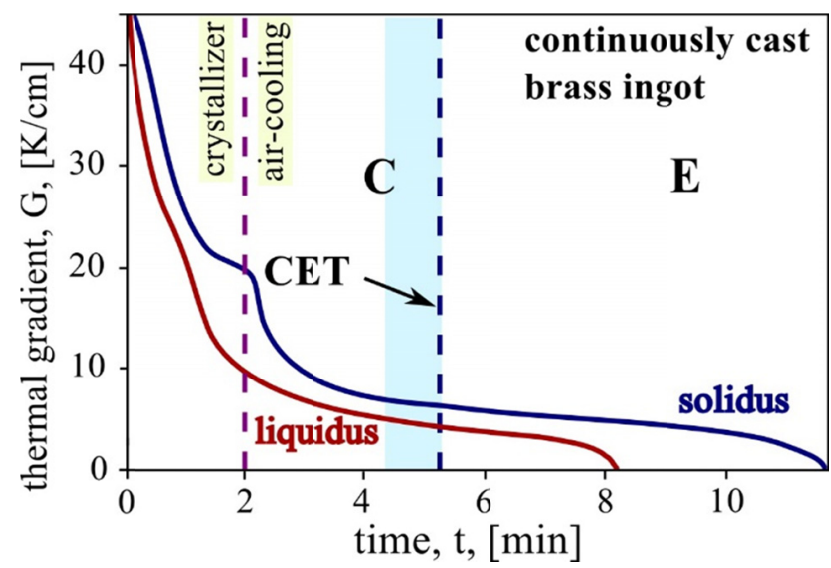

Fig. 4b. Situation of the CET as defined by the points of inflection on the functions of the thermal gradient: $a /$ at the s/l interface which is attached to the tips of growing columnar grains (liquidus isotherm), and $\mathrm{b} /$ at the bottom of the mushy zone (solidus isotherm) marked in Fig. 3 
The postulated mathematical interpretation of simulated functions, Fig. 4, allowed to distinguish the $\mathrm{C}-$ and $\mathrm{E}-$ structural zone, only.

The mathematical treatments, performed in the STSM (Space-Time-Structure Map), Fig. 4a, and on the $G(t)$ - function, Fig. 4b, both should give the same localization of the CET - transition versus solidification time. This comparison satisfactorily confirms that the CET appears at about 5.25 [min] of the process, Fig. 4a, and Fig. 4b.

However, more detailed analysis allows to define a localization of the FCCT - transformation, Fig. 5. The single crystal formation revealed in the brass ingot morphology, Fig. 2a, cannot be yet situated.

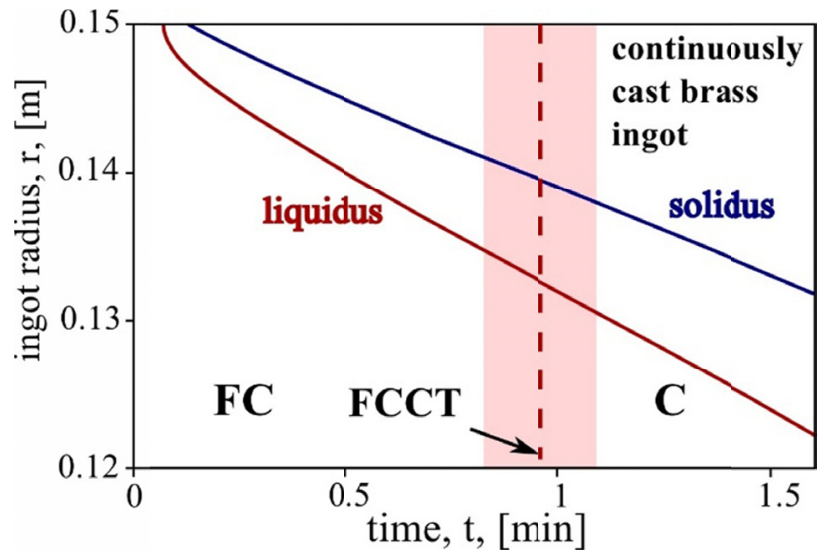

Fig. 5a. Situation of the FCCT - transformation as suggested by the point of inflection on the liquidus isotherm displacement analyzed in the STSM (Space-Time-Structure Map)

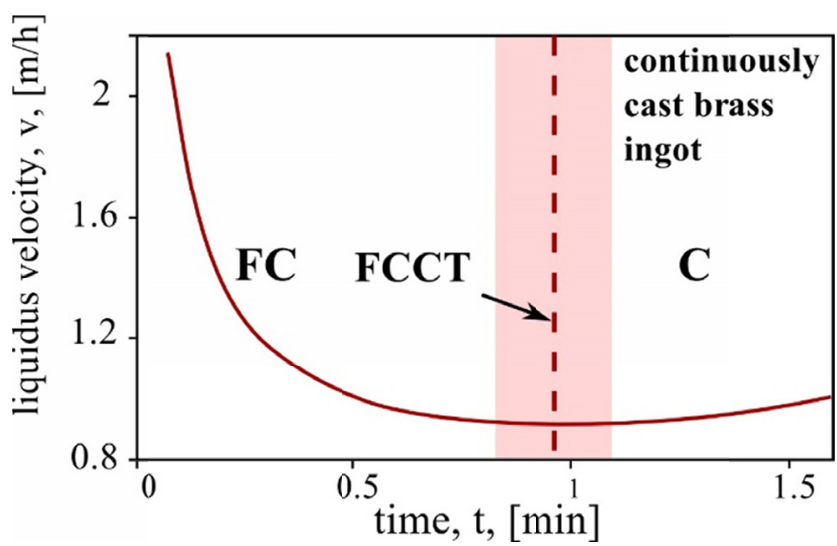

Fig. 5b. Situation of the FCCT as suggested by the local minimum of the function presenting the liquidus velocity of movement versus time

\section{Concluding remarks}

The fully developed model for the heat transfer during continuous casting of ingots is delivered, Eq. (1), Fig. 3. It delivers the mathematical forecast of structural zones appearance in the brass ingot. It follows the newly developed method for structural zones prediction in the solidifying steel static ingot, Fig. 1, [1].

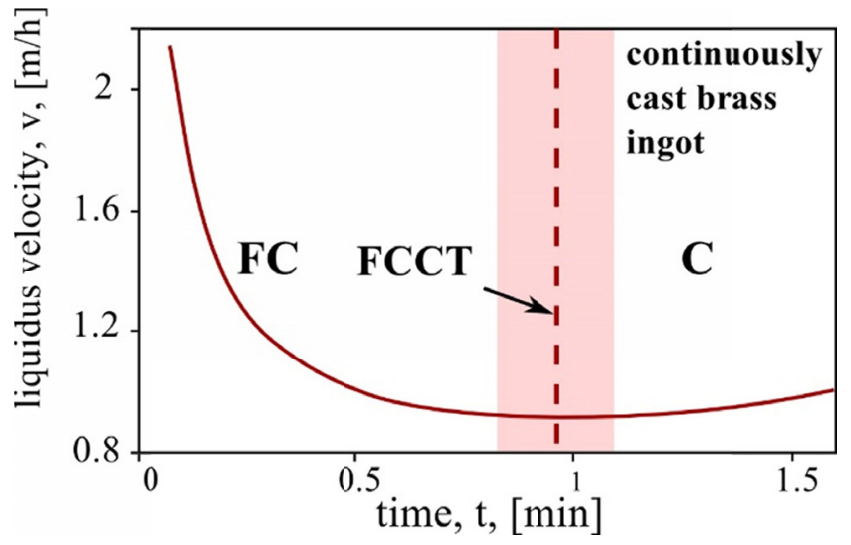

Fig. 5c. Situation of the FCCT as suggested by the point of inflection on the $G(t)$ - function calculated for the moving liquidus isotherm

The results of simulation presented above do not allow to predict the localization of the single crystal which forms axially in the brass ingot when a proper solidification conditions are ensured.

Therefore, it seemed justified to study the influence of the crystallizer height on the liquidus velocity of motion in function of the distance from the liquid brass meniscus.

Thus, the crystallizer height was reduced in the simulation until 0.8 [m], Fig. 6, (usually applied crystallizer in the industry condition is of the $1.2[\mathrm{~m}]$ of height).

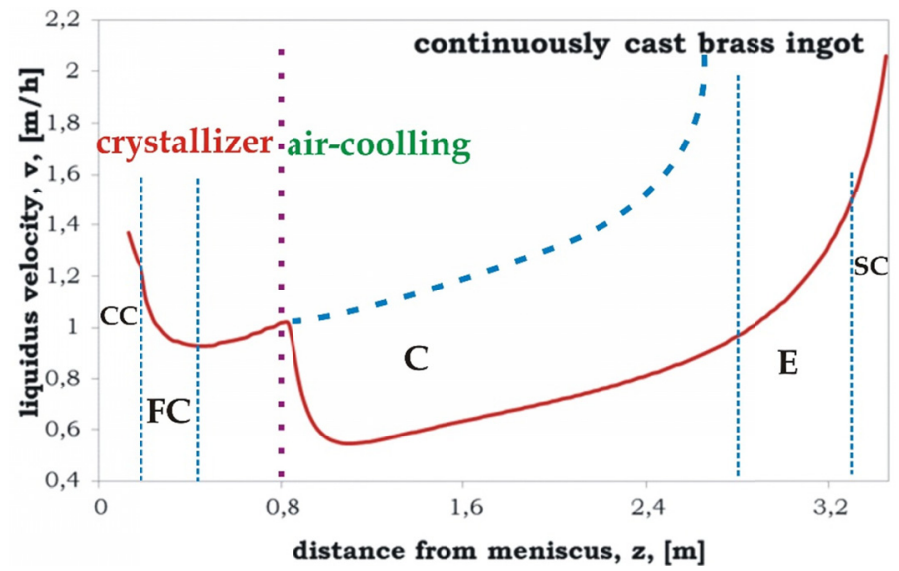

Fig. 6. Liquidus velocity of movement versus distance from the liquid phase meniscus (crystallizer height equal to $0.8[\mathrm{~m}]$ )

The postulated mathematical treatment of the obtained function, Fig. 6, allows to distinguish many structural zones in the brass ingot subjected to continuous casting. There are: $\mathrm{CC}$ - chilled columnar, FC - fine columnar, C - columnar, $\mathrm{E}$ - equiaxed, and $\mathrm{SC}$ - single crystal structure. These structural zones are enough well visible on the transversal section of the brass ingot, Fig. 2a, Fig. 7.

However, when the crystallizer is sufficiently high, then the analyzed function is to be modified (dashed line). The dashed line (being an extension of the original function shown in the $0 \div 0.8$ range of the distance from meniscus), together with the originally simulated function, $v(z)$, (considered in the range: 


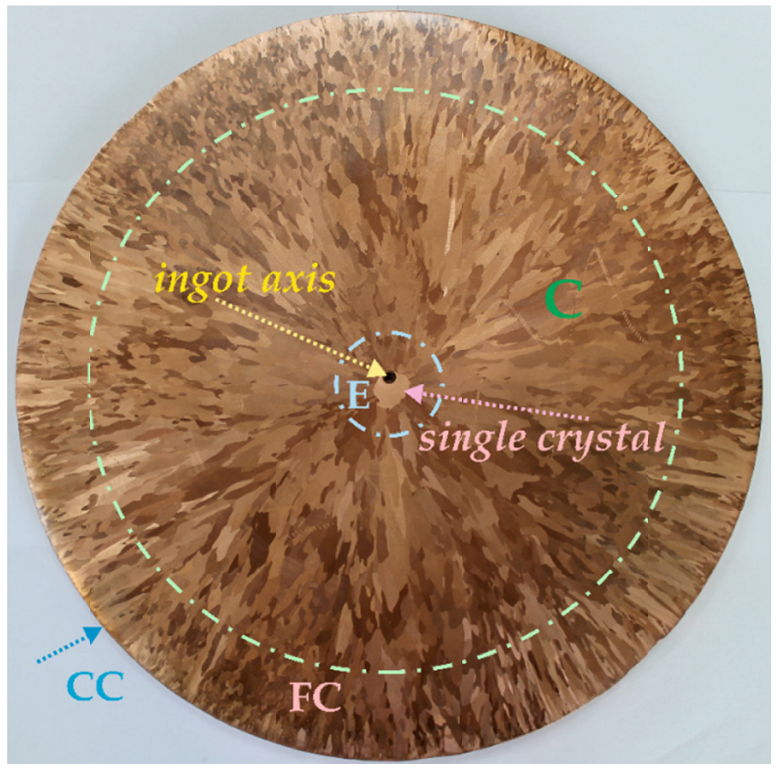

Fig. 7. Structural transformations (structural zones) distinguished in the continuously cast brass ingot adequately to the mathematical forecast shown in Fig. 6

$0 \div 0.8[\mathrm{~m}])$, predicts the following structural zones formation: $\mathrm{CC}, \mathrm{FC}, \mathrm{C}$, only.

Thus, the higher crystallizer is the more possible is the disappearance of the single crystal in the brass ingot.

The above conclusion is illustrated in Fig. 8. Therefore, a new crystallizer height is added and marked, $h=1.2[\mathrm{~m}]$, Fig. 8. Thus, the corresponding middle function $v(z)$ is plotted hypothetically, (dotted line).

It forecasts the appearance of the following structural zones: $\mathrm{CC}, \mathrm{FC}, \mathrm{C}$, and $\mathrm{E}$. The single crystal cannot be formed, as proved.

This hypothetically plotted $v(z)$ - function, Fig. 8, can be simulated due to the current model for heat transfer, Fig. 9.

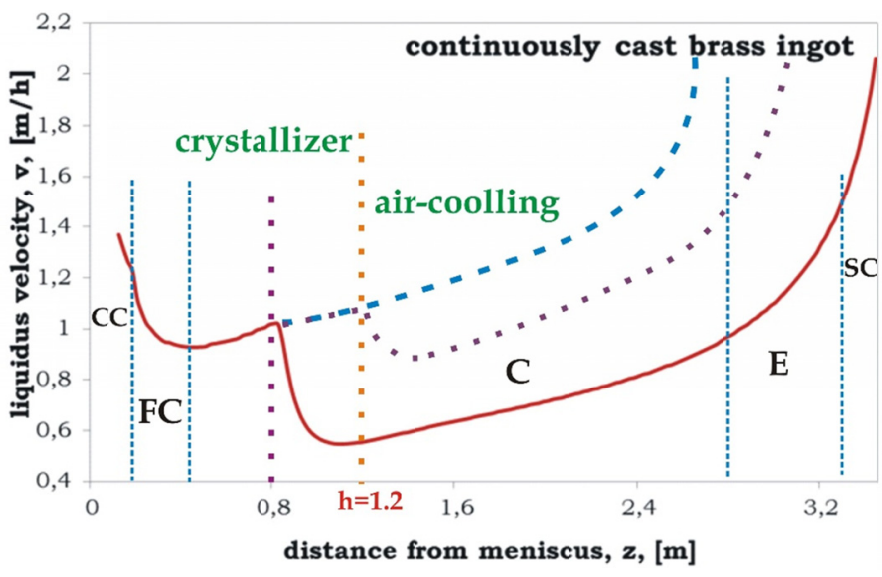

Fig. 8. The $v(z)-$ function a/ for crystallizer height equal to 0.8 [m], $\mathrm{b} /$ for sufficiently high crystallizer (dashed line), c/ for crystallizer height equal to $1.2[\mathrm{~m}]$ (middle-function shown by the dotted line)

The ingots usually contain some insoluble inclusions / intrusive agents (ceramic particles), [36,37]. These hard particles can be swallowed or rejected by the solid / liquid interface during ingot solidification. The required rejection depends on the type of ingot structure (columnar or equiaxed), and first of all, this rejection depends on the solidification rate. When the solidification rate is higher than the threshold rate (characteristic / typical of a given alloy) then the rejection is very intensive, [38].

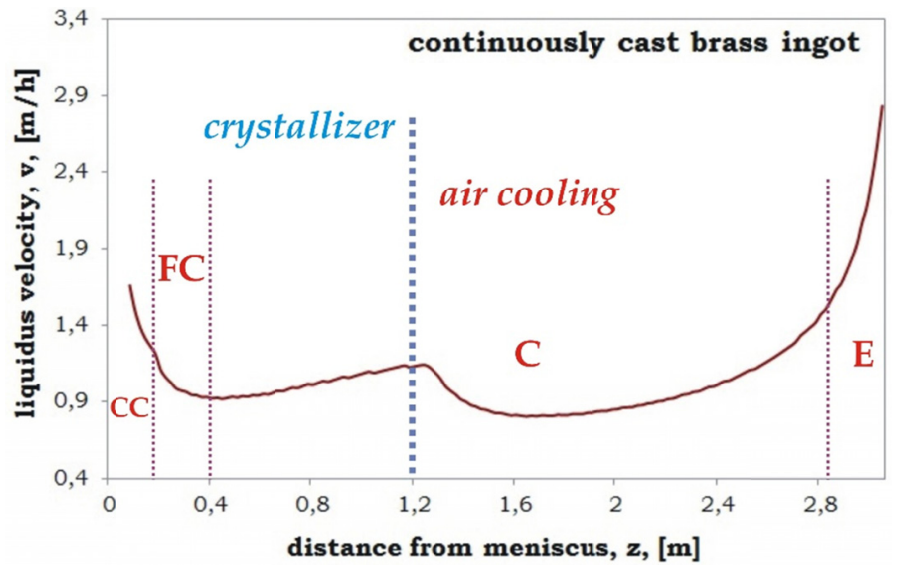

Fig. 9. The simulated $v(z)$ - function for the crystallizer height equal to $1.2[\mathrm{~m}]$; the deflection of the simulated function presents a characteristic delay to the situation of the crystallizer edge

Some advanced methods could be applied to make the diagnosis of a given alloy subjected to melting or solidification, [39]. This kind of diagnosis allows to confirm localization of the defects / inclusions in the alloy morphology. It is suggested that the mentioned method could be employed to study the hard particles motion during castings solidification accompanied by the imposed thermal gradient and crystals growth rate (resulting from the velocity of the casting / ingot translation in the crystallizer) which are usually applied in the industrial conditions.

The threshold rate of solidification was not determined in the presented analysis. However, it can be postulated that the columnar structure and particularly single crystal (situated axially and growing with the rate of an ingot translation in the crystallizer) are more conducive the rejection of insoluble particles / hard particles).

In this case, the hard particles should be pushed away until the end of the continuously cast brass ingot, as expected / required. Therefore, the solidification should be carry out in the way which ensures the formation of columnar structure, exclusively. This situation is well illustrated / determined due to the simulated function and its shifted part illustrated by the dashed line, Fig. 6.

\section{Acknowledgements}

The support was provided by the National Center for Research and Development under Grant No. PBS3/A5/52/2015. The assistance of the steel plant "CELSA - Huta Ostrowiec" in Ostrowiec Świętokrzyski, and in particular, Mr. R. Martynowski, and Mr. S. Binek is greatly appreciated. 


\section{REFERENCES}

[1] W. Wołczyński, Large Steel Ingots: Microstructure Mathematical Modeling. Entry in: The Encyclopedia of Iron, Steel, and Their Alloys, p. 1910-1924, Boca Raton-London-New York, 2016, Taylor \& Francis; R. Colas, G.E. Totten (Eds.).

[2] J.D. Hunt, Steady State Columnar / Equiaxed Growth of Dendrites and Eutectics, Materials Science and Engineering 65, 75-83 (1984).

[3] I.V. Alexandrova, D.V. Alexandrov, D.L. Aseev, S.V. Bulitcheva, Mushy Layer Formation during Solidification of Binary Alloys from a Cooled Wall: the Role of Boundary Conditions. Acta Physica Polonica 115A, 6-9 (2009).

[4] Z. Lipnicki, B. Weigand, Influence of Thermal Boundary Layer on the Contact Layer between Liquid and a Cold Plate in a Solidification Process. Heat and Mass Transfer 47, 1629-1635 (2011).

[5] B. Mochnacki, E. Majchrzak, R. Szopa, Application of the Boundary Element Method for the Numerical Modelling of the Solidification of Cylindrical and Spherical Castings. Journal of Materials Processing Technology 106, 99-106, (2000).

[6] W. Wołczyński, Z. Lipnicki, A.W. Bydałek, A.A. Ivanova, Structural Zones in Large Static Ingots. Forecasts for Continuously Cast Brass Ingot. Archives of Foundry Engineering 16, 141-146 (2016).

[7] L. Konozsy, A. Ishmurzin, M. Grasser, M.H. Wu, A. Ludwig, R. Tanzer, W. Schutzenhofer, Columnar to Equiaxed Transition during Ingot Casting using Ternary Alloy Composition. Materials Science Forum 649, 349-354 (2010).

[8] Ch.A. Gandin, From Constrained to Unconstrained Growth during Directional Solidification. Acta Materialia 48, 2483-2501 (2000).

[9] A. Z. Lorbiecka, B. Sarler, A Sensitivity Study of Grain Growth Model for Prediction of ECT/CET Transformations in Continuous Steel Casting. Materials Science Forum 649, 373-378 (2010).

[10] J. Szajnar, The Columnar Crystals Shape and Castings Structure Cast in Magnetic Field. Journal of Materials Processing Technology 157/158, 761-764 (2004).

[11] A. Burbelko, J. Falkus, W. Kapturkiewicz, K. Sołek, P. Drożdż, M. Wróbel, Modeling of the Grain Structure Formation in the Steel Continuous Ingot by CAFE Method, Archives of Metallurgy and Materials 57, 379-384 (2012).

[12] A.A. Ivanova, Dynamika Tiemperaturnych Gradientow Nieprerywnolitogo Slitka, Metallurgicheskije Processy i Oborudovanije, 2(16), 7-12 (2009).

[13] A.A. Ivanova, Calculation of Phase Change Boundary Position in Continuous Casting. Archives of Foundry Engineering 13, 57-62 (2012).

[14] M. Tkadlečkova, L. Valek, L. Socha, M. Saternus, J. Pieprzyca, T. Merder, K. Michalek, M. Kovac, Study of Solidification of Continuously Cast Steel Round Billets using Numerical Mode, Archives of Metallurgy and Materials 61, 221-226 (2016).

[15] J. Szajnar, M. Stawarz, T. Wróbel, W. Sebzda, Influence of Electromagnetic Field on Pure Metals and Alloys Structure, Journal of Achievements in Materials and Manufacturing Engineering 34, 95-102 (2009).
[16] M. Cholewa, T. Wróbel, S. Tenerowicz, Bimetallic Layers Casting, Journal of Achievements in Materials and Manufacturing Engineering 43, 385-392 (2010).

[17] T. Wróbel, Bimetallic Layered Casting Alloy Steel - Grey Cast Iron, Archives of Materials Science and Engineering 48, 118-125 (2011).

[18] A. Zyska, Z. Konopka,M. Łagiewka, M. Nadolski, Modelling of the Dendritic Crystallization by the Cellular Automaton Method. Archives of Foundry Engineering 16, 99-106 (2016).

[19] E. Majchrzak, B. Mochnacki, M. Dziewoński, M. Jasiński, Identification of Boundary Heat Flux on the Continuous Casting Surface. Archives of Foundry Engineering 8, 105-110 (2008).

[20] T. Telejko, Z. Malinowski, M. Rywotycki, Analysis of Heat Transfer and Fluid Flow in Continuous Steel Casting. Archives of Metallurgy and Materials 54, 837-844 (2009).

[21] T. Lipiński, Improvement of Mechanical Properties of AlSi7Mg Alloy with Fast Cooling Homogeneous Modifier. Archives of Foundry Engineering 8, 85-88 (2008).

[22] K. Suzuki, K. Taniguchi, The Mechanism of Reducing “A” Segregates in Steel Ingots. Transactions of the Iron and Steel Institute of Japan 21, 235-242 (1981).

[23] Ch.A. Gandin, M. Rappaz, R. Tintillier, Three Dimensional Simulation of the Grain Formation in Investment Casting. Metallurgical Transactions 25A, 629-641 (1994).

[24] M.A. Martorano, C. Beckerman, Ch.A. Gandin, Solutal Interaction Mechanism for Columnar-to-Equiaxed Transition in Alloy Solidification. Metallurgical and Materials Transactions 35A, 1915-1922 (2004).

[25] B. Billia, Ch.A. Gandin, G. Zimmerman, D.J. Browne, M. Dupouy, Columnar - Equiaxed Transition in Solidification Processing. Microgravity Science and Technology 16, 290-298 (2005).

[26] H. Nguyen-Thi, B.H. Zhou, G. Reinhart, B. Billia, Q.S. Liu, C.W. Lan, T. Lyubimova, B. Roux, Influence of Forced Convection on Columnar Microstructure during Directional Solidification of Al-Ni Alloys. Materials Science Forum 508, 181-186 (2006).

[27] S. McFadden, D.J. Browne, J. Banaszek, Prediction of the Formation of an Equiaxed Zone ahead of a Columnar Front in Binary Alloys Castings: Indirect and Direct Methods. Materials Science Forum 508, 325-330 (2006).

[28] Y. Miyata, Morphological Transition in High Growth Rate in Constrained Solidification. Materials Science Forum 649, 255-262 (2010).

[29] S. McFadden, D.J. Browne, L. Sturz, G. Zimmermann, Analysis of a Microgravity Experiment for Columnar to Equiaxed Transitions with Modeling Results. Materials Science Forum 649, 361-366 (2010).

[30] G. Zimmermann, L. Sturz, B. Billia, N. Mangelinck-Noel, D.R. Liu, H. Nguyen-Thi, N. Bergeon, Ch.A. Gandin, D.J. Browne, Ch. Beckermann, D. Tourret, A. Karma, Columnar-to-Equiaxed Transition in Solidification Processing of AlSi7 Alloys in Microgravity - CETSOL Project. Materials Science Forum 790/791, 12-21 (2014).

[31] T. Umeda, Heat, Mass and Microstructure Simulation of Continuous Casting. Proceedings of 7-th International Symposium on Physical Simulation, Tsukuba, Japan, June 3-7, 1997, p. 64-75. 
[32] M. M'Hamdi, M. Bobadilla, G. Combeau, G. Lesoult, Numerical Modeling of the Columnar to Equiaxed Transition in Continuous Casting of Steel. Modelling of Casting, Welding and Advanced Solidification Process VIII, Proceedings of the VIII-th Conference on Modeling of Casting, Welding and Advanced Solidification, San Diego, California, USA, June 7-12, 1998, Thomas, B.G. Beckerman, Ch., Eds., T.M.S., Warrendale, Pennsylvania, p. 375.

[33] A.Z. Lorbiecka, B. Sarler, Simulation of Dendritic Growth with Different Orientation by Using the Point Automata Method. Computers, Materials and Continua 18, 69-103 (2010).

[34] J. Stetina, F. Kavicka, T. Mauder, Numerical Model of Heat Transfer and Mass Transfer during Solidification of Concasting Steel. Proceedings of the ASME/JSME 8-th Thermal Engineering Joint Conference - AJTEC, Honolulu, Hawaii, USA, March 13-17, 2011, Eds. ASME/JSME Conference CD, AJTEC-44031, 2.1.
[35] W. Wołczyński, Constrained / Unconstrained Solidification within the Massive Cast Steel / Iron Ingots. Archives of Foundry Engineering 10, 195-202 (2010).

[36] A.M. Zubko, V.G. Lobanov, V.V. Nikonova, Reaction of Foreign Particles with a Crystallization Front. Soviet Physics-Crystallography 18, 239-245 (1973).

[37] D. Shangguan, S. Ahuja, D.M. Stefan's, An Analytical Model for the Interaction between an Insoluble Particle and an Advancing Solid/Liquid Interface. Metallurgical Transactions 23A, 669-706 (1992).

[38] E. Fraś, E. Olejnik, Interaction between Solidification Front and Alien Phase Particles. Archives of Metallurgy and Materials 53, 695-702 (2008).

[39] M. Perzyk, J. Kozłowski, Methodology of Fault Diagnosis in Ductile Iron Melting Process. Archives of Foundry Engineering 16, 101-108 (2016). 